\title{
Separate and concurrent use of 2-deoxy-D-glucose and 3-bromopyruvate in pancreatic cancer cells
}

\author{
HUIJIE XIAO $^{1 *}$, SHASHA LI ${ }^{2 *}$, DAPENG ZHANG ${ }^{3}$, TONGJUN LIU ${ }^{1}$, MING YU $^{4}$ and FENG WANG ${ }^{3,5}$ \\ ${ }^{1}$ Department of Colorectal Surgery, China-Japan Union Hospital of Jilin University, Changchun, Jilin 130033; \\ ${ }^{2}$ Department of Pancreatic Cancer, Tianjin Medical University Cancer Institute and Hospital, Tianjin 300060; \\ ${ }^{3}$ Institute of Chinese and Modern Medicines for Acute Abdominal Diseases, Tianjin Medical University \\ Nankai Hospital, Tianjin 300100; ${ }^{4}$ Department of Nutrition, Tianjin Medical University School of Public Health, \\ Tianjin 300070, P.R. China; ${ }^{5}$ Department of Surgery, Karolinska University Hospital, 14186 Huddinge, Sweden
}

Received August 16, 2012; Accepted September 25, 2012

DOI: 10.3892/or.2012.2085

\begin{abstract}
Unrestrained glycolysis characterizes energy metabolism in cancer cells. Thus, antiglycolytic reagents such as 2-deoxy-D-glucose (2-DG) and 3-bromopyruvate (3-BrPA) may be used as anticancer drugs. In the present study, we examined the anticancer effects of 2-DG and 3-BrPA in pancreatic cancer cells and investigated whether these effects were regulated by hypoxia-inducible factor- $1 \alpha$ (HIF-1 $\alpha)$. To this end, 2-DG and 3-BrPA were administered to wild-type (wt) MiaPaCa2 and Panc-1 pancreatic cancer cells that were incubated under hypoxic (HIF-1 $\alpha$-positive) or normoxic (HIF-1 $\alpha$-negative) conditions. In addition, 2-DG and 3-BrPA were also administered to si-MiaPaCa2 and si-Panc-1 cells that lacked HIF-1 $\alpha$ as a result of RNA interference. Following drug exposure, cell population was measured using a viability assay. Both HIF- $1 \alpha$-positive and HIF- $1 \alpha$-negative $\mathrm{MiaPaCa} 2$ cells were further studied for their expression of $\mathrm{Cu} / \mathrm{Zn}$-superoxide dismutase (SOD1) and poly(ADP-ribose) polymerase (PARP) and for their contents of ATP and fumarate. In the viability assay, either 2-DG or 3-BrPA decreased the tested cells. Concurrent use of 2-DG and 3-BrPA resulted in a greater decrease of cells and also facilitated ATP depletion. In addition, 3-BrPA was seen to both decrease SOD1 and increase fumarate, which suggests that the reagent impaired the mitochondria. 3-BrPA also decreased both full-length PARP and cleaved PARP, which suggests that 3-BrPA-induced decrease in cell population was a result of cell necrosis rather than apoptosis. When HIF-1 $\alpha$ was induced in wt-MiaPaCa2
\end{abstract}

Correspondence to: Professor Feng Wang, Institute of Chinese and Modern Medicines for Acute Abdominal Diseases, Tianjin Medical University Nankai Hospital, Tianjin 300100, P.R. China E-mail: wangf730@gmail.com

*Contributed equally

Key words: pancreatic cancer, 2-deoxy-D-glucose, 3-bromopyruvate, hypoxia-inducible factor- $1 \alpha$, glycolysis, hexokinase cells by hypoxia, some effects of 2-DG and 3-BrPA were attenuated. We conclude that: i) concurrent use of 2-DG and 3-BrPA has better anticancer effects in pancreatic cancer cells, ii) 3-BrPA impairs the mitochondria of pancreatic cancer cells and induces cell necrosis, and iii) HIF- $1 \alpha$ regulates the anticancer effects of 2-DG and 3-BrPA in pancreatic cancer cells.

\section{Introduction}

Cancer cells grow more rapidly than tumoral blood vessels (1). This characteristic of cancer cells induces an intra-tumoral hypoxia (2) that in turn decreases the growth of cancer cells. When cancer cell growth is decreased, so is the cell's sensitivity to oncologic therapies $(3,4)$.

Mammalian cells produce energy primarily by oxidative phosphorylation (OXPHOS) and to a lesser extent by glycolysis. Cancer cells have increased glucose transporters, glycolytic enzymes and the proteins that inhibit OXPHOS. As a result, cancer cells have high levels of glycolysis and low levels of OXPHOS. Therefore, cancer cells switch their primary pathway of energy production from OXPHOS to glycolysis. This phenomenon was first described by Warburg (5) and is known as the Warburg effect. Mechanisms of the Warburg effect are poorly defined and may involve the transcription factor hypoxia-inducible factor-1 (HIF-1) (6).

HIF-1 comprises $\alpha$ and $\beta$ subunits (7). Upon biosynthesis, HIF- $1 \alpha$ is hydroxylated in the presence of oxygen and is then degraded in proteasomes (8). Thus, normal mammalian cells have HIF-1 $\beta$ but not HIF-1 $\alpha$. When cells are subjected to hypoxia, however, HIF-1 $\alpha$ is stabilized and associated with HIF-1 $\beta$. Thus, intra-tumoral hypoxia appears to be causally responsible for HIF-1 $\alpha$ expression that is seen in different cancer cells (6). In addition, cancer cells may have an increased HIF-1 $\alpha$ production (9). When cancer cells produce more HIF-1 $\alpha$ than they can degrade, HIF-1 $\alpha$ is accumulated. HIF-1 $\alpha$ expression increases glucose transporters, glycolytic enzymes, and the inhibitors of OXPHOS. Therefore, cancerinduced HIF-1 $\alpha$ plays a key role in the Warburg effect (10-13).

As the first step of glycolysis, glucose is phosphorylated by hexokinase to produce glucose-6-phosphate (G-6-P). Next, G-6-P is converted to fructose-6-phosphate by phosphoglu- 
cose isomerase (PGI). In cancer cells, the predominant form of hexokinase is hexokinase-2 (HK-II) that is attached to the outer membrane of the mitochondria (12). Inhibition of HK-II not only decreases energy production but also impairs the mitochondria in cancer cells. Several HK-II inhibitors have been developed, including 2-deoxy-D-glucose (2-DG) and 3-bromopyruvate (3-BrPA) (14-25).

After 2-DG is transported in cancer cells by overexpressed glucose transporters, it is phosphorylated by HK-II to produce 2-DG-6-phosphate (2-DG-6-P). However, this product cannot be metabolized further, so it accumulates in cancer cells and inhibits HK-II by allosteric feedback. Meanwhile, nonphosphorylated 2-DG competes with glucose for binding to HK-II, and the substrate competition inhibits HK-II as well. Furthermore, 2-DG-6-P competes with G-6-P for binding to PGI, and the second substrate competition inhibits PGI (14). Unlike 2-DG, 3-BrPA is an alkylating reagent that inactivates HK-II and dissociates the enzyme from the mitochondria (21). When 2-DG or 3-BrPA is used alone or in combination with other anticancer drugs, cancer cells are inhibited (15-25). However, it is unclear whether 2-DG and 3-BrPA have enhanced anticancer effects when they are used together. Here, we addressed this question in MiaPaCa2 and Panc-1 pancreatic cancer cells.

When cells are subjected to hypoxia, they undergo biological changes to adapt themselves to the hypoxic conditions. Whilst many of the hypoxia-induced changes are mediated by HIF-1 $\alpha$, some hypoxia-induced changes may be independent of HIF-1 $\alpha$ (26). In the present study, we studied wild-type (wt) $\mathrm{MiaPaCa} 2$ and Panc-1 cells when they were incubated under hypoxic (HIF-1 $\alpha$-positive) or normoxic (HIF-1 $\alpha$-negative) conditions and we also studied MiaPaCa2 and Panc-1 variants that had HIF-1 $\alpha$-specific small interfering RNA (siRNA) and were devoid of HIF-1 $\alpha$ in both normoxia and hypoxia. By comparing data from the different cells, we differentiated the hypoxia-induced changes that were dependent on HIF-1 $\alpha$ from those that were independent of HIF-1 $\alpha$. In different experiments, we measured cell population, determined intracellular ATP and fumarate, and assessed the expression of HIF-1 $\alpha$, HK-II, Cu/Zn-superoxide dismutase (SOD1), and poly(ADPribose) polymerase (PARP).

\section{Materials and methods}

Pancreatic cancer cells. Wt MiaPaCa2 and Panc-1 cells were obtained from the American Type Culture Collection (Rockville, MD, USA). The MiaPaCa2 and Panc-1 cells that had HIF-1 $\alpha$-specific siRNA (namely si-MiaPaCa2 and si-Panc-1) were prepared as we previously described (10). In different assays, cells were plated in different vessels and were cultured at $37^{\circ} \mathrm{C}$ in $5 \% \mathrm{CO}_{2}$ and $95 \%$ air (normoxia), using Dulbecco's modified Eagle's medium with $10 \%$ fetal bovine serum. When cells were $80 \%$ confluent, they were subjected to experimental incubation in which they were exposed to 2-DG (\#D3179; Sigma) and 3-BrPA (\#16490; Sigma) in normoxia or hypoxia. Hypoxic incubation $\left(1 \% \mathrm{O}_{2}, 5 \% \mathrm{CO}_{2}\right.$ and $\left.94 \% \mathrm{~N}_{2}\right)$ was set up as previously described (10).

Western blotting. Whole-cell proteins were extracted using RIPA lysis and extraction buffer (Thermo Scientific). In
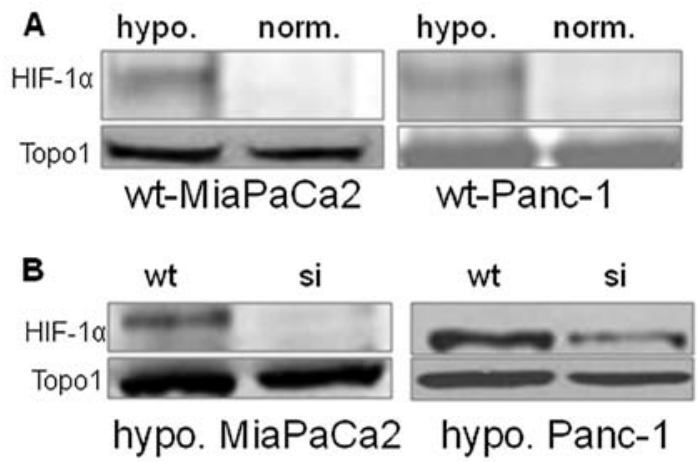

Figure 1. HIF-1 $\alpha$ was determined by western blot analysis, using Topol as a loading control. (A) HIF-1 $\alpha$ in wild-type (wt) MiaPaCa2 and Panc-1 cells that were cultured under hypoxic or normoxic conditions. (B) HIF-1 $\alpha$ in hypoxic si-MiaPaCa2 and si-Panc-1 cells, using hypoxic wt cells as positive controls.

some experiments, nuclear proteins were extracted (10). Proteins were separated on $8 \%$ SDS gel and transferred to PVDF membranes. HIF-1 $\alpha$ was determined either in nuclear proteins using a monoclonal anti-HIF-1 $\alpha$ antiserum (\#610958; BD Biosciences) or in whole-cell proteins using a polyclonal antiserum (\#100-449; Novus). HK-II, SOD1 and PARP were determined in whole-cell proteins, using antisera from Santa Cruz Biotechnology Inc., (\#6521), StressMarq Biosciences Inc., (SPC-115C/D) and Cell Signaling Technology (\#9532). Topo1, $\beta$-actin and glyceraldehyde 3-phosphate dehydrogenase (GAPDH) were determined as loading controls, using antisera from TopoGEN, Inc., (\#2012-2) and Abcam (\#8227 and \#9483). Secondary antisera were produced by Amersham (\#NA931 and \#NA934) and Chemicom (\#AP106P). Each protein was assayed at least 3 times.

MTT viability assay. Cells in 96-well plates were exposed to: i) 2-DG alone (0.3-18 mM), ii) 3-BrPA alone (50-200 $\mu \mathrm{M})$, iii) both 3-BrPA (50-200 $\mu \mathrm{M})$ and 2-DG $(1 \mathrm{mM})$, or iv) neither 2-DG nor 3-BrPA (control) for $22 \mathrm{~h}$ in normoxic or hypoxic conditions. After a solution of 3-(4,5-dimethylthiazol-2-yl)2,5-diphenyltetrazolium bromide (MTT, $5 \mathrm{mg} / \mathrm{ml}$ ) was added (10 $\mu \mathrm{l} /$ well), all cells were incubated in normoxia for $2 \mathrm{~h}$. The cells were dissolved in isopropanol with $4 \mathrm{mM} \mathrm{HCl}$, and MTT values were read in a spectrophotometer using a wavelength of $570 \mathrm{~nm}$.

Other assays. MiaPaCa2 cells were plated either in 24-well plates for ATP assay or in Petri dishes for fumarate assay. During experimental incubation, cells were exposed for $4 \mathrm{~h}$ to 2-DG alone (4 mM), 3-BrPA alone (25 $\mu \mathrm{M})$, both 2-DG $(1 \mathrm{mM})$ and 3-BrPA $(25 \mu \mathrm{M})$, or neither 2-DG nor 3-BrPA. ATP and fumarate were determined using BioVision kits \#354 and \#633 (Mountain View, CA, USA). Proteins were determined using a BCA assay kit.

Statistical analysis. Data are the means \pm SEM. When three or more groups were involved, results were analyzed using analysis of variance followed by the Student's t-test. When two groups were involved, the Student's t-test was used. $\mathrm{P}<0.05$ was considered to indicate statistically significant differences. 
A MiaPaCa2

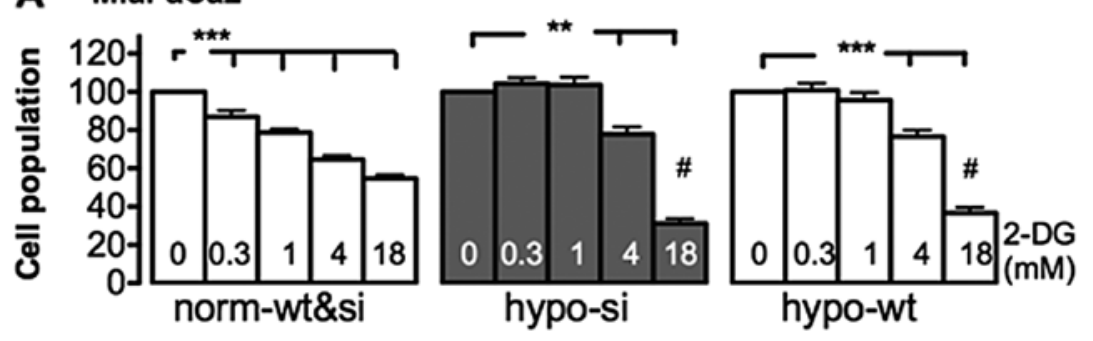

B Panc-1

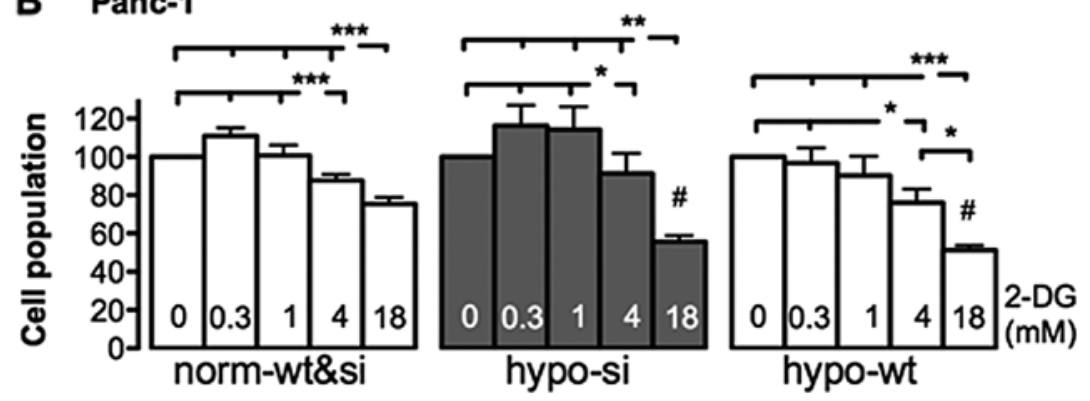

Figure 2. (A) MiaPaCa2 and (B) Panc-1 cells were exposed to 0-18 mM 2-DG in normoxia or hypoxia for $22 \mathrm{~h}$. After MTT was added, all cells were incubated in normoxia for $2 \mathrm{~h}$. MTT values were determined to measure the size of the cell population. Assays were performed for $\geq 14$ times in MiaPaCa2 cells and $\geq 10$ times in Panc-1 cells. Each time, cell cultures were prepared in triplicates. Data were calculated using control-cell (0 mM $2-\mathrm{DG})$ values as $100 \%$. ${ }^{*} \mathrm{P}<0.05$, ${ }^{* *} \mathrm{P}<0.01$ and ${ }^{* * *} \mathrm{P}<0.001$. "Significant difference $(\mathrm{P}<0.001)$ between indicated hypoxic cells and their normoxic counterparts
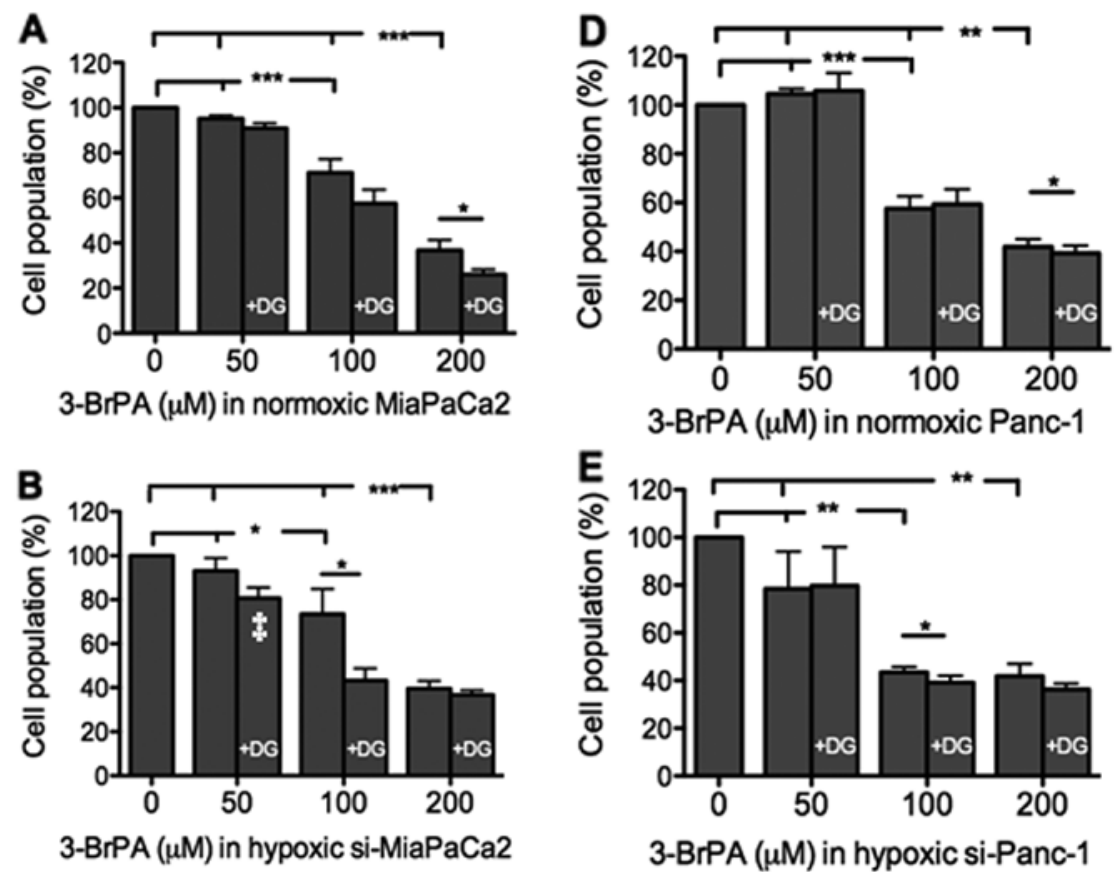

3-BrPA $(\mu \mathrm{M})$ in hypoxic si-Panc-1
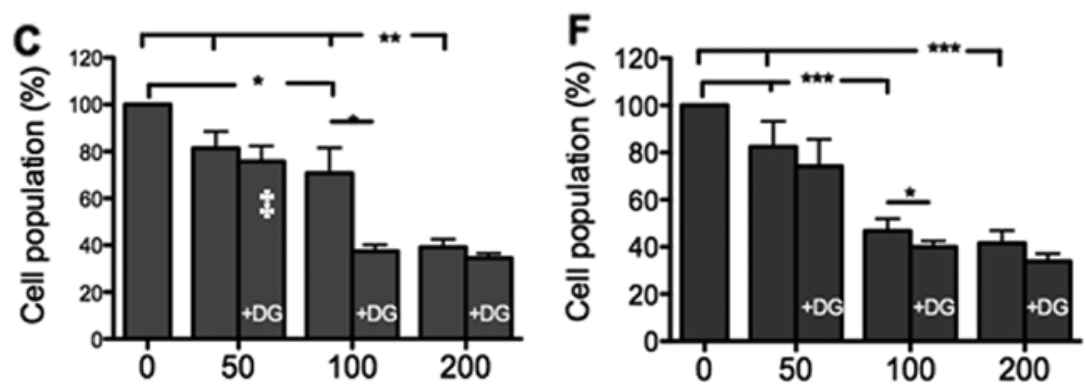

3-BrPA $(\mu \mathrm{M})$ in hypoxic wt-MiaPaCa2

3-BrPA $(\mu \mathrm{M})$ in hypoxic wt-Panc-1

Figure 3. (A-C) MiaPaCa2 and (D-F) Panc-1 cells were treated with 3-BrPA (50-200 $\mu \mathrm{M})$ in the absence and presence of additional 2-DG (1 mM). Control cells were treated without 2-DG and 3-BrPA. Please see the Fig. 2 legend for details. ${ }^{*} \mathrm{P}<0.05,{ }^{* *} \mathrm{P}<0.01$ and ${ }^{* * *} \mathrm{P}<0.001$. ${ }^{*}$ Significant difference $(\mathrm{P}<0.001)$ between indicated cells and controls $(0 \mu \mathrm{M} 3-\mathrm{BrPA})$. 

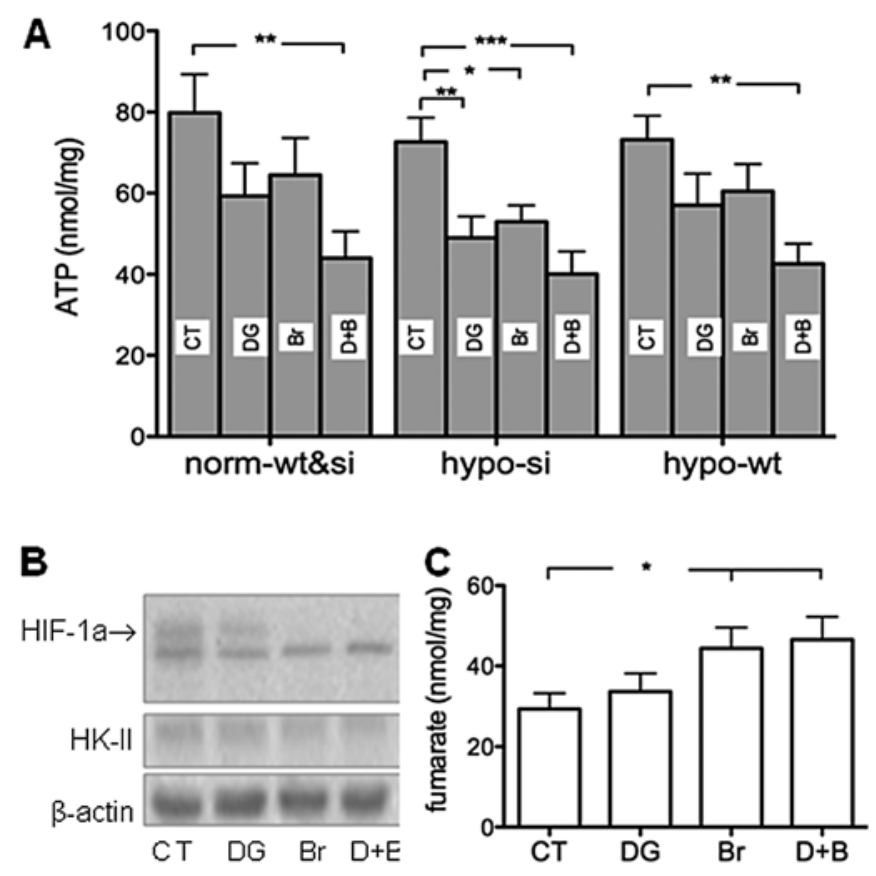

Figure 4. Three types of MiaPaCa2 cells underwent a 4-h exposure to 2-DG alone (4 mM, DG), 3-BrPA alone ( $25 \mu \mathrm{M}, \mathrm{BP})$, both 2-DG (1 mM) and 3-BrPA $(25 \mu \mathrm{M})(\mathrm{D}+\mathrm{B})$, or neither 2-DG nor 3-BrPA (CT). (A) ATP, (B) HIF-1 $\alpha$, HK-II, and $(C)$ fumarate were determined. ATP and fumarate data were normalized with protein contents (in mg). ${ }^{*} \mathrm{P}<0.05,{ }^{* *} \mathrm{P}<0.01$ and ${ }^{* * *} \mathrm{P}<0.001$.

\section{Results}

HIF-1 $\alpha$ expression in studied cells. Wt-MiaPaCa2 and wt-Panc-1 cells expressed HIF-1 $\alpha$ in hypoxia but not normoxia (Fig. 1A). As a result of RNA interference, HIF-1 $\alpha$ expression was completely inhibited in hypoxic si-MiaPaCa2 cells and largely inhibited in hypoxic si-Panc-1 cells (Fig. 1B). Neither si-MiaPaCa2 cells nor si-Panc-1 cells had HIF-1 $\alpha$ in normoxia (data not shown).

Effects of 2-DG and 3-BrPA on cell viability. Given that neither wt-MiaPaCa2 nor si-MiaPaCA2 cells had HIF-1 $\alpha$ in normoxia, these normoxic cells were essentially identical in terms of HIF-1 $\alpha$ expression. Thus, although these normoxic cells (i.e., wt and si cells) were incubated separately during MTT assay, data from them were pooled and are shown in the same groups. As shown in the left panel in Fig. 2A, normoxic $\mathrm{MiaPaCa} 2$ cells were decreased by each of the four 2-DG concentrations tested (0.3-, 1-, 4- and 18-mM). In hypoxia, however, significant decreases were seen when si-MiaPaCa2 and wt-MiaPaCa2 cells were exposed to the two highest 2-DG concentrations but not the lower ones (Fig. 2A). Thus, the lowest effective dose of 2-DG for hypoxic MiaPaCa2 cells (4 mM) was higher than that for normoxic cells $(0.3 \mathrm{mM})$, which suggests that hypoxia decreased 2-DG sensitivity. When cell-inhibiting effects of 2-DG were compared across different cell types, $18 \mathrm{mM}$ 2-DG induced greater cell decrease in hypoxic MiaPaCa2 cells, than in normoxic ones (Fig. 2A). When different types of Panc-1 cells underwent the same 2-DG treatment, they were all decreased by the two highest concentrations of 2-DG (4 and $18 \mathrm{mM}$ ). Thus, normoxic Panc- 1 cells were less sensitive to 2-DG than normoxic MiaPaCa2 cells, as
A

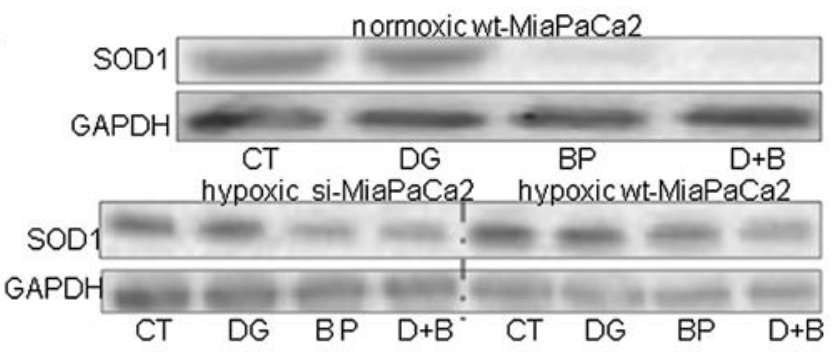

B
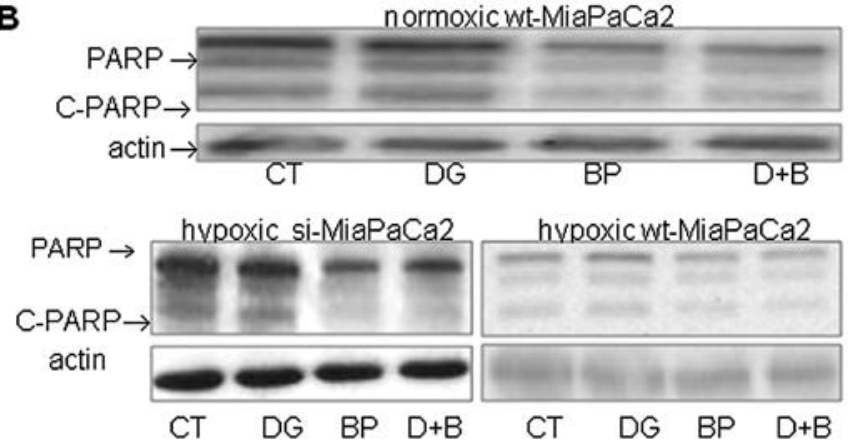

Figure 5. Three types of MiaPaCa2 cells underwent a 4-h exposure to 2-DG alone (4 mM, DG), 3-BrPA alone (25 $\mu \mathrm{M}, \mathrm{BP})$, both 2-DG (1 mM) and 3-BrPA $(25 \mu \mathrm{M})(\mathrm{D}+\mathrm{B})$, or neither 2-DG nor 3-BrPA (CT). (A) SOD1 and (B) PARP were determined by western blot analysis, using GAPDH and $\beta$-actin as loading controls. c-PARP, cleaved PARP.

reported in a previous study (15). In addition, $18 \mathrm{mM}$ 2-DG decreased Panc-1 cells more in hypoxia, than in normoxia (Fig. 2B).

When used alone, $50 \mu \mathrm{M}$ 3-BrPA did not decrease any $\mathrm{MiaPaCa} 2$ cells (Fig. 3A-C). When $50 \mu \mathrm{M} 3-\mathrm{BrPA}$ was combined with $1 \mathrm{mM}$ 2-DG, however, significant decreases were seen in hypoxic wt- and si-MiaPaCa2 cells (Fig. 3B and C). When 3-BrPA was increased to 100-200 $\mu \mathrm{M}$, all MiaPaCa2 cells were decreased, and the cell decrease was further augmented by additional 2-DG (Fig. 3A-C). When Panc-1 cells were subjected to the same assay, results were similar to those seen in MiaPaCa2 cells (Fig. 3D-F).

Mechanisms underlying the cell decrease induced by 2-DG and 3-BrPA. Separate use of 2-DG and 3-BrPA significantly decreased ATP in hypoxic si-MiaPaCa 2 cells but not in any wt-MiaPaCa2 cells (Fig. 4A). When 3-BrPA and 2-DG were combined, significant decreases in ATP were seen in all cell types (Fig. 4A). When HIF-1 $\alpha$ and HK-II were determined in hypoxic wt-MiaPaCa2 cells, we found that 2-DG decreased HIF-1 $\alpha$ in a moderate manner but had no effects on HK-II (Fig. 4B). By contrast, 3-BrPA decreased HIF-1 $\alpha$ profoundly in both the absence and presence of 2-DG, and also decreased HK-II in the same cells (Fig. 4B). When fumarate was determined in hypoxic wt-MiaPaCa2 cells, we found that $3-\mathrm{BrPA}$ increased this mitochondrial metabolite in both the absence and presence of 2-DG (Fig. 4C).

2-DG did not change SOD1 in any cells tested, whereas 3-BrPA decreased this antioxidant enzyme in both the absence and presence of 2-DG (Fig. 5A). Furthermore, the SOD1 decrease was more pronounced in two HIF-1 $\alpha$-negative cell types, than in hypoxic wt-MiaPaCa2 cells (Fig. 5A). When 
PARP was determined, we used an antiserum that recognized both full-length PARP (116 kDa) and a cleaved PARP molecule (c-PARP, $89 \mathrm{kDa}$ ). 2-DG did not change PARP contents, whereas 3-BrPA decreased PARP and c-PARP in both the absence and presence of 2-DG (Fig. 5B).

\section{Discussion}

When different cancer cells were exposed to 2-DG or 3-BrPA in previous studies, exposure times ranged from 6 to $96 \mathrm{~h}$, with $24 \mathrm{~h}$ being the usual choice (15-18,20-24). In the MTT assay, we exposed cells to 2-DG and 3-BrPA for $24 \mathrm{~h}$. The 2-DG and 3-BrPA concentrations we used were comparable to those used by others $(15-18,20-24)$.

When cancer cells are stressed by hypoxia, they increase glucose transporters and glycolytic enzymes to augment energy production by glycolysis. Thus, hypoxia may decrease the sensitivity of cancer cells to the reagents that inhibit glycolysis by substrate competition and/or by allosteric feedback. This may explain why hypoxic MiaPaCa2 cells were less sensitive to 2-DG than their normoxic counterparts. Markedly, the hypoxia-induced decrease in 2-DG sensitivity was seen in both wt- and si-MiaPaCa2 cells, which suggests that the decrease in 2-DG sensitivity was independent of HIF-1 $\alpha$.

In a previous study, hypoxic conditions downregulated more than 100 genes in mouse fibroblasts, with many of the genes being related to cell viability (26). This suggests that hypoxia has negative effects on cell viability. Normally, these negative effects may be masked by hypoxia-induced beneficial effects on cell biology, such as increased glycolysis and energy production. When antiglycolytic reagents completely inhibit glycolysis, however, the hypoxia-induced effects on cell viability are revealed. This explains why $18 \mathrm{mM}$ 2-DG decreased cells to greater extents in hypoxia, than it did in normoxia.

When 3-BrPA was used alone in $50 \mu \mathrm{M}$, it did not affect the tested cells. However, when $50 \mu \mathrm{M} 3$-BrPA was combined with $1 \mathrm{mM}$ 2-DG, hypoxic MiaPaCa2 cells were decreased. Of note, $1 \mathrm{mM}$ 2-DG did not decrease the hypoxic cells when it was used independently. Thus, concurrent use of 2-DG $(1 \mathrm{mM})$ and 3-BrPA $(50 \mu \mathrm{M})$ decreased the lowest effective doses of both reagents. When 3-BrPA was used in higher concentrations (100-200 $\mu \mathrm{M})$, its anticancer effects were also augmented by the additional 2-DG. Since 2-DG and 3-BrPA inhibit glycolysis by different molecular mechanisms (14), these mechanisms might cooperate when the two antiglycolytic reagents are used simultaneously.

When stressed by hypoxia, HIF-1 $\alpha$-negative si-MiaPaCa 2 cells were unable to increase glycolysis adequately. This may explain why separate use of 2-DG and 3-BrPA only decreased ATP in the HIF-1 $\alpha$-negative cells. When glycolysis was completely inhibited by concurrent use of 2-DG and 3-BrPA, however, significant decreases in ATP were seen in all cell types. Thus, the present ATP data suggest that HIF- $1 \alpha$ helped cells maintain ATP contents.

HIF- $1 \alpha$ in hypoxic wt-MiaPaCa2 cells was moderately inhibited by 2 -DG and profoundly inhibited by $3-\mathrm{BrPA}$. The mechanisms underlying the HIF-1 $\alpha$ inhibition are unclear. However, the data suggest that 2-DG and 3-BrPA compromised cancer cells not only by inhibiting glycolysis but also by decreasing HIF-1 $\alpha$ expression. In 3-BrPA-treated cells, the HIF-1 $\alpha$ decrease may be responsible for the concomitant decrease in HK-II expression.

In cancer cells, defects in the mitochondria may increase mitochondrial metabolites such as fumarate and succinate (29). As a result, these metabolites may exit mitochondria and accumulate in the cytosol. Since fumarate and succinate inhibit HIF-1 $\alpha$ degradation, their accumulation in the cytosol may be associated with an increased HIF-1 $\alpha$ expression (29). In the present study, however, 3-BrPA was seen to both increase fumarate and decrease HIF-1 $\alpha$. Thus, it appears that fumarate did not play a key role in HIF-1 $\alpha$ expression by MiaPaCa2 cells. The increase in fumarate may be a result of impairments in the mitochondria of the 3-BrPA-treated cells. In a recent study, 3-BrPA was shown to inhibit mitochondrial respiration in hepatocellular carcinoma cells (26).

Whole-cell SOD1 levels are an index of mitochondrial integrity (30). In the present study, SOD1 was decreased in 3-BrPA-treated cells, which suggests that 3-BrPA impaired the mitochondria (27). Furthermore, 3-BrPA-induced SOD1 decreases were more pronounced in two HIF- $1 \alpha$-negative MiaPaCa2 cell types, than in hypoxic wt-MiaPaCa2 cells. This suggests that HIF- $1 \alpha$ protected mitochondria from 3-BrPA-induced damages. Apoptosis and necrosis are two cell-death modalities. When cancer cells undergo apoptosis, they show decreased PARP and increased c-PARP (28). When cancer cells undergo necrosis, their PARP contents are normal or decreased, and their c-PARP contents are not increased $(22,31)$. In this light, the present PARP data suggest that 3-BrPA killed MiaPaCa 2 cells by necrosis. In a previous study, 3-BrPA was found to induce necrosis in melanoma cells (32).

In summary, the present study shows that concurrent use of 2-DG and 3-BrPA increases anticancer effects of these antiglycolytic reagents; it also demonstrates that hypoxia and HIF-1 $\alpha$ regulate 2-DG and 3-BrPA effects. Addition of an HIF-1 $\alpha$ inhibitor to combined 2-DG and 3-BrPA may further increase the anticancer effects of these antiglycolytic reagents.

\section{Acknowledgements}

The authors are grateful for the financial support from the Tianjin Qian-Ren program.

\section{References}

1. Folkman J: Tumor angiogenesis: therapeutic implications. N Engl J Med 285: 1182-1186, 1971.

2. Koong AC, Mehta VK, Le QT, et al: Pancreatic tumors show high levels of hypoxia. Int J Radiat Oncol Biol Phys 48: 919-922, 2000.

3. Erler JT, Cawthorne CJ, Williams KJ, et al: Hypoxia-mediated down-regulation of Bid and Bax in tumors occurs via hypoxiainducible factor 1-dependent and -independent mechanisms and contributes to drug resistance. Mol Cell Biol 24: 2875-2889, 2004.

4. Brown JM, Diehn M and Loo BW Jr: Stereotactic ablative radiotherapy should be combined with a hypoxic cell radiosensitizer. Int J Radiat Oncol Biol Phys 78: 323-327, 2010.

5. Warburg O: On the origin of cancer cells. Science 123: 309-314, 1956.

6. Zhong H, De Marzo AM, Laughner E, et al: Overexpression of hypoxia-inducible factor 1alpha in common human cancers and their metastases. Cancer Res 59: 5830-5835, 1999.

7. Semenza GL and Wang GL: A nuclear factor induced by hypoxia via de novo protein synthesis binds to the human erythropoietin gene enhancer at a site required for transcriptional activation. Mol Cell Biol 12: 5447-5454, 1992. 
8. Salceda S and Caro J: Hypoxia-inducible factor 1alpha (HIF-1alpha) protein is rapidly degraded by the ubiquitinproteasome system under normoxic conditions. Its stabilization by hypoxia depends on redox-induced changes. J Biol Chem 272 : 22642-22647, 1997.

9. Fukuda R, Hirota K, Fan F, et al: Insulin-like growth factor 1 induces hypoxia-inducible factor 1-mediated vascular endothelial growth factor expression, which is dependent on MAP kinase and phosphatidylinositol 3-kinase signaling in colon cancer cells J Biol Chem 277: 38205-38211, 2002.

10. Wang F, Li SS, Segersvärd R, et al: Hypoxia inducible factor-1 mediates effects of insulin on pancreatic cancer cells and disturbs host energy homeostasis. Am J Pathol 170: 469-477, 2007.

11. Natsuizaka M, Ozasa M, Darmanin S, et al: Synergistic up-regulation of Hexokinase-2, glucose transporters and angiogenic factors in pancreatic cancer cells by glucose deprivation and hypoxia. Exp Cell Res 313: 3337-3348, 2007.

12. Mathupala SP, Ko YH and Pedersen PL: Hexokinase-2 bound to mitochondria: cancer's stygian link to the 'Warburg Effect' and a pivotal target for effective therapy. Semin Cancer Biol 19 17-24, 2009.

13. Kirito K, Hu Y and Komatsu N: HIF-1 prevents the overproduction of mitochondrial ROS after cytokine stimulation through induction of PDK-1. Cell Cycle 8: 2844-2849, 2009.

14. Kurtoglu M, Maher JC and Lampidis TJ: Different toxic mechanisms of 2-deoxy-D-glucose versus 2-fluorodeoxy-D-glucose in hypoxic and normoxic tumor cells. Antioxid Redox Signal 9: 1383-1390, 2007

15. Maher JC, Savaraj N, Priebe W, et al: Differential sensitivity to 2-deoxy-D-glucose between two pancreatic cell lines correlates with GLUT-1 expression. Pancreas 30: e34-e39, 2005.

16. Wangpaichitr M, Savaraj N, Maher J, et al: Intrinsically lower AKT, mTOR and HIF activity correlates with increased sensitivity to 2-deoxy-D-glucose under hypoxia in lung cancer cell lines. Mol Cancer Ther 7: 1506-1513, 2008.

17. Maher JC, Wangpaichitr M, Savaraj N, et al: Hypoxia-inducible factor-1 confers resistance to the glycolytic inhibitor 2-deoxy-Dglucose. Mol Cancer Ther 6: 732-741, 2007.

18. Hernlund E, Ihrlund LS, Khan O, et al: Potentiation of chemotherapeutic drugs by energy metabolism inhibitors 2-deoxyglucose and etomoxir. Int J Cancer 123: 476-483, 2008.

19. Maschek G, Savaraj N, Priebe W, et al: 2-Deoxy-D-glucose increases the efficacy of adriamycin and paclitaxel in human osteosarcoma and non-small cell lung cancers in vivo. Cancer Res 64: 31-34, 2004.
20. Ko YH, Pedersen PL and Geschwind JF: Glucose catabolism in the rabbit VX2 tumor model for liver cancer: characterization and targeting hexokinase. Cancer Lett 173: 83-91, 2001.

21. Chen Z, Zhang H, Lu W and Huang P: Role of mitochondriaassociated hexokinase II in cancer cell death induced by 3-bromopyruvate. Biochim Biophys Acta 1787: 553-560, 2009.

22. Kim JS, Ahn KJ, Kim JA, et al: Role of reactive oxygen speciesmediated mitochondrial dysregulation in 3-bromopyruvate induced cell death in hepatoma cells: ROS-mediated cell death by 3-BrPA. J Bioenerg Biomembr 40: 607-618, 2008.

23. Hulleman E, Kazemier KM, Holleman A, et al: Inhibition of glycolysis modulates prednisolone resistance in acute lymphoblastic leukemia cells. Blood 113: 2014-2021, 2009.

24. Ko YH, Smith BL, Wang Y, et al: Advanced cancers: eradication in all cases using 3-bromopyruvate therapy to deplete ATP. Biochem Biophys Res Commun 324: 269-275, 2004.

25. Pereira da Silva AP, El-Bacha T, Kyaw N, et al: Inhibition of energy-producing pathways of HepG2 cells by 3-bromopyruvate. Biochem J 417: 717-726, 2009.

26. Greijer AE, van der Groep P, Kemming D, et al: Up-regulation of gene expression by hypoxia is mediated predominantly by hypoxia-inducible factor 1 (HIF-1). J Pathol 206: 291-304, 2005.

27. Indran IR, Tufo G, Pervaiz S and Brenner C: Recent advances in apoptosis, mitochondria and drug resistance in cancer cells. Biochim Biophys Acta 1807: 735-745, 2011

28. Mangerich A and Bürkle A: How to kill tumor cells with inhibitors of poly(ADP-ribosyl)ation. Int J Cancer 128: 251-265, 2011.

29. Koivunen P, Hirsilä M, Remes AM, et al: Inhibition of hypoxia-inducible factor (HIF) hydroxylases by citric acid cycle intermediates: possible links between cell metabolism and stabilization of HIF. J Biol Chem 282: 4524-4532, 2007.

30. Liang HL, Sedlic F, Bosnjak Z and Nilakantan V: SOD1 and MitoTEMPO partially prevent mitochondrial permeability transition pore opening, necrosis, and mitochondrial apoptosis after ATP depletion recovery. Free Radic Biol Med 49: 1550-1560, 2010.

31. Ha HC and Snyder SH: Poly(ADP-ribose) polymerase is a mediator of necrotic cell death by ATP depletion. Proc Natl Acad Sci USA 96: 13978-13982, 1999.

32. Qin JZ, Xin H and Nickoloff BJ: 3-Bromopyruvate induces necrotic cell death in sensitive melanoma cell lines. Biochem Biophys Res Commun 396: 495-500, 2010. 